\title{
The Role of Tagana in Disaster Education for Public Elementary School 2 Wates, Ponorogo
}

\author{
Risma Dwi Arisona1', Rohana Sufia² \\ ${ }^{1}$ Institut Agama Islam Negeri Ponorogo, ${ }^{2}$ Sekolah Tinggi Agama Islam Al-Fithrah \\ arisona@iainponorogo.ac.id
}

Article History

accepted 31/08/2020

approved 22/09/2020

published 28/10/2020

\begin{abstract}
The focus of this research is to describe the role of Tagana in disaster education and the obstacles it faces in providing disaster education for elementary school students. This research is a qualitative descriptive study. This research was conducted at SDN 2 Wates Ponorogo. Data collection techniques through observation, interviews, literature study, and documentation. Data analysis used the Mile and Huberman analysis model. The results showed that the role of Tagana in disaster education for elementary school students can be seen from the Tagana Goes to School program. The program aims to accelerate the building of students' understanding and preparedness for disasters so as to minimize the impact. In the program, the roles of Tagana are: 1) providing knowledge of the types of disasters to students; 2) providing knowledge of disaster mitigation according to the type of disaster, and 3) conducting disaster mitigation simulations. In this case, disaster education is more focused on earthquake disasters. Meanwhile, the obstacles faced by the Tagana Goes to School team were limited personnel and lack of response from the school. For this reason, additional volunteers must be carried out and disaster preparedness cadres formed in schools, so that the program can run effectively and efficiently.
\end{abstract}

Keywords: Tagana, education, and disaster.

\begin{abstract}
Abstrak
Fokus penelitian ini adalah mendeskripsikan bagaimana peran Tagana dalam pendidikan kebencanaan dan hambatan yang dihadapi dalam upaya memberikan pendidikan kebencanaan bagi siswa sekolah dasar. Penelitian ini merupakan penelitian deskriptif kualitatif. Penelitian ini dilakukan di SDN 2 Wates Ponorogo. Teknik pengumpulan data melalui observasi, wawancara, studi pustaka, dan dokumentasi. Analisis data menggunakan model analisis Mile and Huberman. Hasil penelitian menunjukkan bahwa peran Tagana dalam pendidikan kebencanaan bagi siswa sekolah dasar dapat terlihat dari program Tagana Goes to School. Program tersebut bertujuan untuk mempercepat terbangunnya pemahaman dan kesiapsiagaan siswa terhadap bencana sehingga meminimalisir dampak yang ditimbulkan. Dalam program tersebut, peran Tagana adalah: 1) memberikan pengetahuan terhadap jenis-jenis bencana kepada siswa; 2) memberikan pengetahuan terhadap mitigasi bencana sesuai dengan jenis becananya, dan 3) melakukan simulasi mitigasi bencana. Dalam kasus ini, pendidikan kebencaanan lebih difokuskan pada bencana gempa bumi. Sedangkan untuk hambatan yang dihadapi tim Tagana Goes to School adalah keterbatasan personil dan kurangnya respon dari pihak sekolah. Untuk itu, penambahan relawan harus dilakukan dan dibentuk kader-kader siaga bencana di sekolah, sehingga program tersebut dapat berjalan dengan efektif dan efisien.
\end{abstract}

Kata kunci: Tagana, pendidikan, dan kebencanaan.

Social, Humanities, and Education Studies (SHEs): Conference Series https://jurnal.uns.ac.id/shes

p-ISSN 2620-9284

e-ISSN 2620-9292 


\section{PENDAHULUAN}

Taruna Siaga Bencana (Tagana) adalah salah satu organisasi kebencanaan yang berada di bawah naungan Kementrian Sosial. Menurut Pasal 1 ayat (1) Peraturan Menteri Sosial RI (Permensos RI) No. 29 Tahun 2012 tentang Tagana, menjelaskan bahwa Tagana adalah relawan sosial atau Tenaga Kesejahteraan Sosial berasal dari masyarakat yang memiliki kepedulian dan aktif dalam penanggulangan bencana bidang perlindungan sosial. Tagana bertujuan untuk meningkatkan partisipasi masyarakat dalam penanggulangan bencana. Tagana juga memiliki tugas membantu Pemerintah dan Pemerintah daerah dalam melaksanakan penanggulangan bencana baik pada saat prabencana, saat tanggap darurat maupun saat pasca bencana serta tugas-tugas penanganan permasalahan sosial lainnya yang terkait dengan penanggulangan bencana.

Pada Pasal 7 Permensos RI No. 29 Tahun 2012, menjelaskan bahwa Tagana dalam melaksanakan penanggulangan bencana pada fase pra bencana mempunyai fungsi, antara lain: a) Pendataan dan pemetaan daerah rawan bencana; b) Peningkatan kapasitas masyarakat dalam pengurangan risiko bencana; $c$ ) Pengurangan risiko bencana di lokasi rawan bencana; d) Peningkatan kesiapsiagaan masyarakat dalam menghadapi kemungkinan terjadi bencana; e) Fasilitasi dalam pembentukan dan pengembangan kampung siaga bencana; f) Pendeteksian dini kepada masyarakat atas kemungkinan terjadi bencana; g) Evakuasi bersama pihak terkait terlebih dalam bidang perlindungan sosial atas ancaman bahaya; $h$ ) Pengurangan risiko dan kesiapsiagaan lainnya.

Menurut Kementrian Pendidikan dan Kebudayaan RI (2016) data United Nation International Strategy For Disaster dmenyebutkan 60 persen anak-anak di dunia merupakan korban bencana alam. Hal tersebut tentu menjadi permasalahan serius yang harus segera ditangani. Salah satu penanganannya adalah dengan kegiatan pendidikan kebencanaan, sehingga mereka akan paham terhadap bencana dan bagaimana upaya mitigasi bencannya.

Pengurangan risiko bencana melalui jalur pendidikan harus segera dilakukan. Sekolah sebagai institusi pendidikan sudah seharusnya memberikan pengetahuan kecakapan keterampilan untuk menghadapi bencana. Oleh karena itu, pendidikan bencana pada anak sekolah dasar merupakan langkah awal dalam membangun masyarakat sadar bencana. Sehingga ketika terjadi bencana siswa tidak lagi kebingungan, panik, karena telah memahami bagaimana cara mengurangi risiko bencana.

Pendidikan kebencanaan pada anak sekolah dasar memerlukan media yang tepat agar mereka dapat memahami mitigasi bencana secara benar. Penanaman mitigasi bencana sejak dini di sekolah dapat dilakukan dengan menggunakan bantuan cerita bergambar, latihan simulasi ringan, maupun menyisipkan materi mitigasi bencana ke dalam materi pelajaran yang sesuai. Pemberdayaan anak sekolah dasar untuk memahami mitigasi bencana merupakan langkah awal dalam membangun masyarakat sadar bencana. Dengan harapan pengetahuan yang didapat dari sekolah dapat ditularkan pada lingkungan sekitar dalam rangka mengurangi risiko bencana

Carter (1991) menjelaskan bahwa komunitas masyarakat tertentu dapat mempengaruhi beberapa komunitas di satu waktu yang sama dan komunitas ini disebut "disaster front". Oleh karena itu, setiap organisasi penanggulangan bencana harus memenuhi partisipasi atau keterlibatan masyarakat yang sesuai. "Disaster front" dapat dijelaskan sebagai garda terdepan dalam penanggulangan bencana. Oleh karena itu, pada tingkat masyarakatlah yang paling terdepan pada sistem manajemen bencana karena masyarakat yang paling mengetahui karakter tempat tinggal dan keadaan sosial yang ada. Hal ini penting dalam manajemen bencana terutama pada level mitigasi. 
Pada kenyataan dilapangan, pendidikan kebencanaan belum masuk pada kurikulum sekolah dasar. Hal tersebut tentu menjadi permasalahan tersendiri. Tidak masuknya pendidikan kebencanaan pada pembelajaran di sekolah dasar, akibatnya pendidikan kebencanaan hanya merupakan tambahan apabila sekolah menghendaki. Selain itu, tidak adanya pembinaan guru maupun pihak-pihak terkait di sekolah mengakibatkan pendidikan kebencanaan tidak dilaksanakan pada tingkat sekolah dasar. Jarang sekali sekolah yang secara mandiri melakukan pembinaan kearah pendidikan kebencanaan. Oleh karena itu, Tagana merupakan organisasi yang dapat memberikan pendidikan kebencanaan pada anak sekolah dasar.

Tagana merupakan suatu organisasi yang memiliki struktur, tujuan, pembagian tugas, hak, dan kewajiban yang jelas. Pembagian tugas erat kaitannya dengan peran yang akan dilaksanakan. Abdulsyani (2012:94) menjelaskan bahwa peranan adalah suatu perbuatan seseorang atau sekelompok orang dalam usaha menjalankan hak dan kewajibannya sesuai dengan status yang dimilikinya. Artinya, anggota Tagana ikut berperan penting dalam usaha meminimalkan resiko bencana melalui pendidikan kebencanaan.

Menurut Setyowati (2019) menjelaskan bahwa pendidikan kebencanaan merupakan bagian dari gerakan guna mengatasi efek bencana, di antaranya dengan cara mempersiapkan generasi yang sadar dan arif melalui sebuah proses pendidikan yang memiliki muatan-muatan penyadaran terhadap bencana. Salah satu upaya yang dilakukan untuk menyampaikan informasi mengenai bencana dan pendidikan kebencanaan adalah sosialisasi bencana yang dilakukan di sekolah guna meminimalkan resiko bencana.

Hasil penelitian yang dilakukan Rahman (2016) menyatakan bahwa peran Tagana dalam pendidikan kebencanaan bagi masyarakat Serang dan Banten. Pendidikan kebencanaan yang dilakukan, yakni mulai dari penilaian terhadap bahaya, informasi bencana bahkan sistem manajemen penanggulangan bencana pada level komunitas masyarakat. Tentu hal tersebut tidak lepas dari peran Tagana dalam memberikan pendidikan mitigasi bencana bagi masyarakat.

Selain itu, penelitian yang dilaksanakan oleh $A B$, Syamsuddin, dan DN, Syakhruddin (2018) yang menyatakan bahwa peran mahasiswa sebagai anggota Tagana dalam bentuk persiapan becana yaitu keaktivan melaksanakan pelatihan dan praktek taruna siaga bencana baik itu praktek tahap pra bencana, latihan dan praktek tanggap darurat, dan latihan dan praktek pendampingan sosial. Sehingga tercipta generasi yang tangguh bencana di Fakultas Dakwah dan Komunikasi UIN Alauddin Kabupaten Gowa. Untuk itu, berdasarkan pemaparan latar belakang diatas peneliti tertarik untuk mengetahui pera Tagana dalam Pendidikan kebencanaan. Tujuan penelitan ini, adalah untuk mengetahui: 1) bagaimana peran Tagana dalam pendidikan kebencanaan bagi siswa sekolah dasar, dan 2) hambatan yang dihadapi dalam pelaksanaan pendidikan kebencanaan bagi siswa sekolah dasar.

\section{METODE}

Penelitian ini merupakan penelitian deskriptif kualitatif. Penelitian ini dilakukan di SDN 2 Wates Ponorogo. Data yang digunakan merupakan data-data yang berasal dari data primer dan sekunder. Data primer berupa hasil wawancara dengan informan relawan Tagana dinas sosial. Keseluruhan berjumlah tiga informan. Sedangkan data sekunder dikumpulkan dari literatur buku dan jurnal yang mengkaji tentang peran Tagana dalam pendidikan kebencanaan. Teknik pengumpulan data melalui observasi, wawancara, studi pustaka, dan dokumentasi. Analisis data menggunakan model analisis Miles and Huberman. Analisis data dilakukan pada saat pengumpulan data berlangsung dan setelah selesai pengumpulan data. Miles and Huberman mengemukakan bahwa analisis data kualitatif dilakukan secara terus menerus sampai tuntas sehingga datanya jenuh (Sugiyono, 2009). Analisis data melalui tahapan reduksi 
data, penyajian data dan penarikan kesimpulan. Validitas data yang digunakan dalam penelitian ini adalah triangulasi. Triangulasi adalah teknik pemeriksaan data yang memanfaatkan sesuatu yang lain. Di luar data itu untuk keperluan pengecekan atau pembanding terhadap data-data itu (Sugiyono, 2009). Triangulasi digunakan untuk membandingkan hasil wawancara dan observasi, sehingga hasil penelitian tidak bertolak belakang dengan fakta dan realitas yang ada.

\section{Peran Tagana dalam Pendidikan Kebencanaan \\ HASIL DAN PEMBAHASAN}

Peran Tagana dalam pendidikan kebencanaan bagi siswa sekolah dasar dapat terlihat dari program Tagana Goes to School. Program tersebut bertujuan untuk mempercepat terbangunnya pemahaman dan kesiapsiagaan siswa terhadap bencana sehingga meminimalisir dampak yang ditimbulkan. Dalam program tersebut, peran Tagana adalah:

1) Memberikan pengetahuan terhadap jenis-jenis bencana kepada siswa;

Relawan Tagana akan menjelaskan kepada siswa-siswi Sekolah Dasar tentang pengetahuan terhadap jenis-jenis bencana. Hal tersebut bertujuan untuk pengenalan jenis-jenis bencana yang ada disekitar mereka, sehingga mereka akan memahami bahwa bencana tidak hanya bencana alam saja. Undang-Undang Nomor 24 Tahun 2007 mendefinisikan jenis bencana meliputi bencana alam, bencana nonalam, dan bencana sosial. Akan tetapi, dalam kegiatan ini lebih ditekankan pada bencana alam.

Bencana alam adalah salah satu faktor yang bisa mengakibatkan rusaknya lingkungan hidup. Bencana alam bila dilihat dari penyebabnya, dapat dibedakan sedikitnya menjadi tiga jenis, yaitu geologis, klimatologis, dan ekstra-terestial. Berikut adalah macam-macam bencana alam yang terjadi di Indonesia, diantaranya: Tsunami, Banjir, Kebakaran, Longsor, Gunung Berapi, Kekeringan dan Abrasi.

Pengenalan terhadap jenis-jenis bencana kepada siswa-siswi Sekolah Dasar akan membentuk konsep tentang pengetahuan bencana. Harapannya mereka dapat mengantisipasi apa yang harus dilakukan jika bencana tersebut terjadi. Pada pelaksaan pemberian materi pengetahuan jenis-jenis bencana disampaikan menggunakan bahasa yang mudah dimengerti siswa dan lebih banyak menggunakan gambar-gambar yang menarik. Seperti pada gambar 1 .

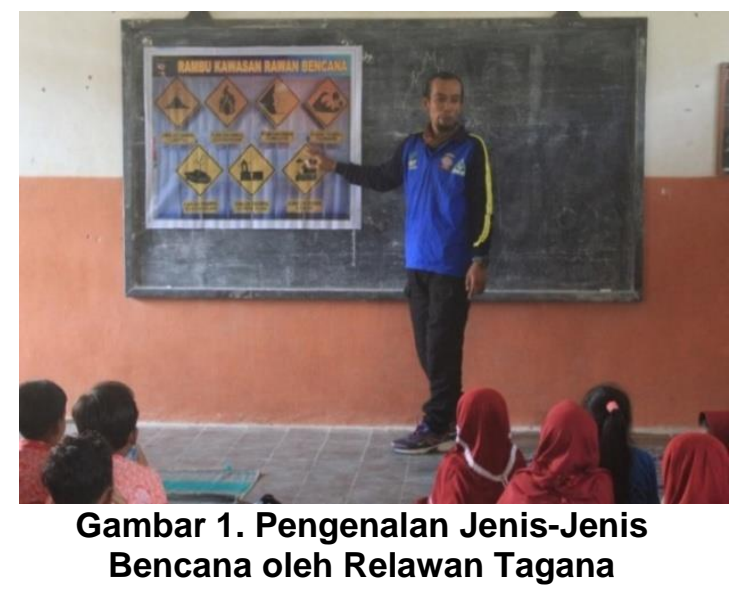

\section{2) Memberikan Pengetahuan terhadap Mitigasi Bencana Sesuai dengan Jenis Bencananya}

Setelah siswa mengetahui tentang jenis-jenis bencana, tim Tagana akan mengenalkan tentang mitigasi bencana sesuai dengan jenis bencananya. Namun, 
karena keterbatasan waktu mitigasi bencana lebih ditekannkan pada bencana gempa bumi.

Materi mitigasi bencana gempa bumi yang disampaikan pada kegiatan Tagana Goes to School pada saat sebelum gempa bumi. Menurut BNPB (2012), beberapa hal yang harus diperhatikan Sebelum Terjadi Gempa Bumi, yaitu: 1) mengetahui sosialisasi tentang gempabumi, mempelajari penyebab gempa; 2) membuat konstruksi rumah tahan gempa; 3) memperhatikan sistem peringatan dini dan membuat sistem peringatan dini mandiri, seperti mengikat benda-benda yang tergantung dengan kuat; 4) melaksanakan dan mengikuti simulasi; 5) mengetahui dimana informasi gempa bisa didapatkan yaitu: BMKG, TV, Radio, ORARI, dll, dan 6) Menyiapkan "tas siaga bencana". Dengan Memperhatikan Langkah-langkah sebelum terjadi gemap bumi tersebut, diharapkan siswa dapat meminimalisir resiko bencana yang terjadi. Kegiatan tersebut dapat dilihat pada gambar 2.

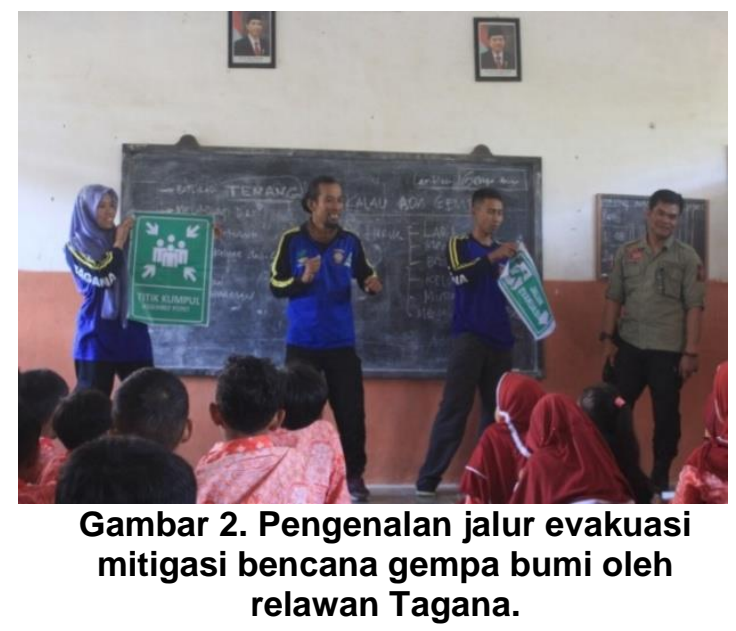

\section{3) Melakukan Simulasi Mitigasi Bencana}

Simulasi mitigasi bencana pada kegiatan Pendidikan kebencanaan yang dilakukan oleh Tagana lebih berfokus pada simulasi mitigasi bencana gempa bumi. Simulasi mitigasi bencana gempa bumi dipilih karena Kabupaten Ponorogo juga merupakan daerah yang rawan gempa. Tercatat gempa bumi beberapa kali terjadi di Kabupaten Ponorogo yang menandakan terdapat sesar aktif. Pada tanggal 10 Pebruari 2011, Pusat Gempa Nasional merilis telah terjadi gempabumi dengan kekuatan 2,6 Skala Richter dengan lokasi $31 \mathrm{Km}$ Tenggara Madiun, kedalaman $10 \mathrm{Km}$, dirasakan di Trenggalek dan Ponorogo (Tim Peneliti Puslitbang, 2011). Selanjutnya pada tanggal 04 November 2016, gempa bumi tektonik mengguncang wilayah Madiun yang getarannya sampai Ponorogo. Hasil analisis BMKG menyebutkan gempa bumi terjadi dengan kekuatan 4,9 Skala Richter pada kedalaman $19 \mathrm{Km}$ yang disebabkan aktivitas sesar aktif di sebelah utara Gunung Lawu (BMKG, 2016).

Kegiatan simulasi mitigasi bencana gempa bumi yang dilaksanakan oleh relawan Tagana didahului dengan pengenalan jalur evakuasi. Jalur evakuasi ini telah dibuat oleh tim Tagana di sekolah, sehingga sebelum pelaksanaan simulasi mitigasi bencana gempa bumi siswa sudah paham dimana atau arah jalur evakuasinya. Jalur evakuasi ini menuju titik kumpul,yaitu di lapangan sekolah.

Pada saat pelaksanaan simulasi mitigasi bencana gempa bumi siswa tetap dengan tertib mendengar arahan dari tim Tagana. Arahan saat terjadi gempa bumi tersebut antara lain:

a) Siswa jangan panik.

b) Berlindung dibawah meja, jika tidak ada meja lindungi kepala atau organ vital dengan tangan atau tas. 
c) Siswa yang berada di dekat pintu keluar segera keluar.

d) Mendahulukan siswa perempuan keluar terlebih dahulu.

e) Berkumpul di titik kumpul sampai bantuan datang.

f) Berdoa.

Siswa dapat melaksanakan arahan yang diberikan dengan baik, sehingga kegiatan simulasi mitigasi bencana gempa bumi dapat berjalan sesuai dengan arahan. Kegiatan ini diulang-ulang sampai tiga kali pengulangan. Tujuannya agar siswa benarbenar terlatih menghadapi situasi bencana gempa bumi sehingga dapat meminimalisir korban. Kegiatan simulasi mitigasi bencana gempa bumi dapat dilihat pada gambar 3.

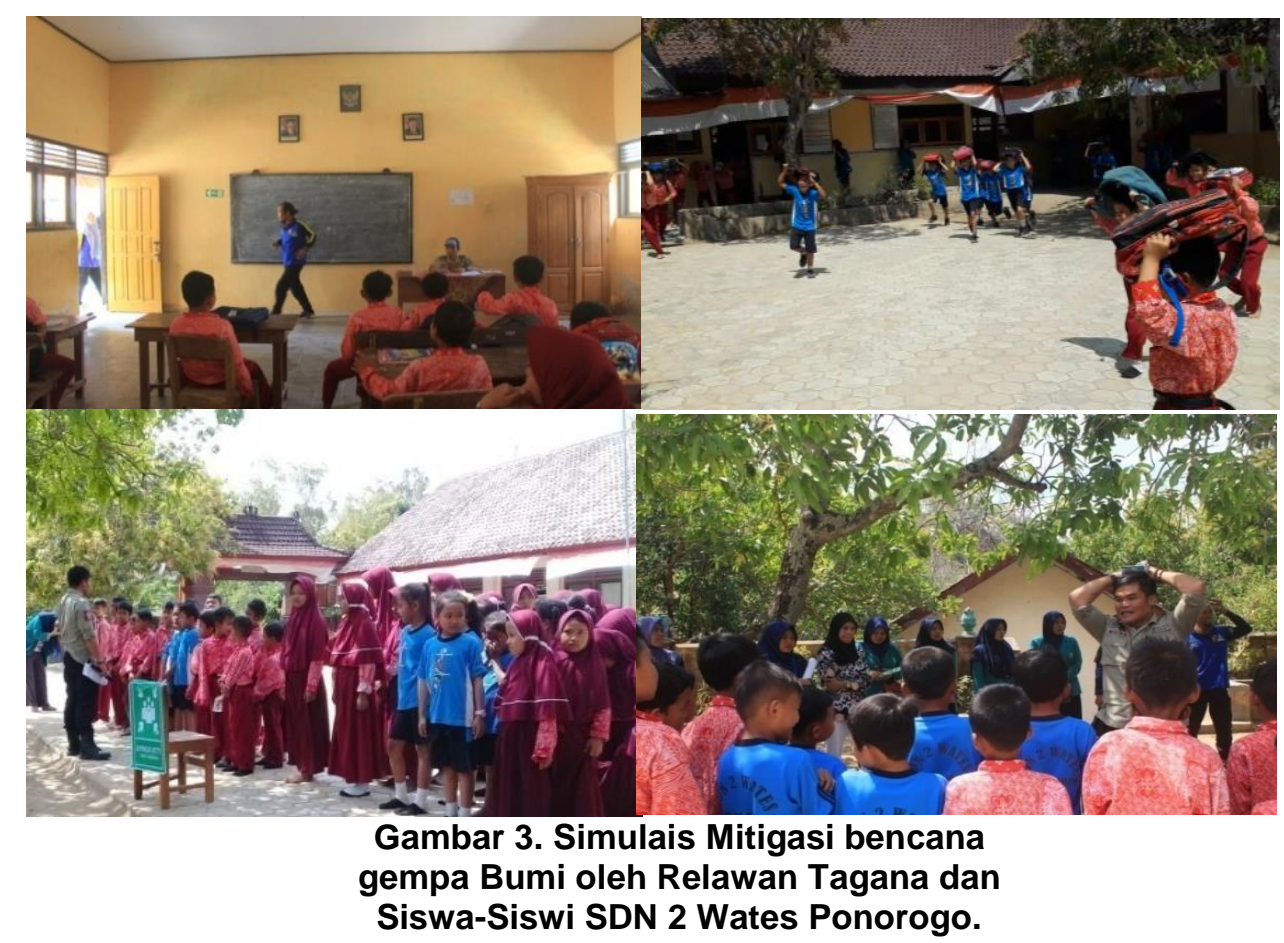

\section{Hambatan-hambatan Tagana dalam Pendidikan Kebencanaan}

1) Keterbatasan Personil Relawan Tagana

Data yang tercatat pada tahun 2019 di Dinas Sosial Kabupaten Ponorogo terdapat 50 relawan anggota Tagana. Relawan anggota Tagana berasal dari berbagai latar belakang, seperti mahasiswa, swasta, dan lain-lain. Anggota Tagana yang bersifat relawan berdampak pada efektifitas program Tagana Goes To School. Dampaknya karena kesibukan relawan tidak semua dapat berpartisipasi aktif dalam program tersebut. Tentu hal tersebut menjadi hambatan dalam pelaksanaan program dan menghambat pendidikan kebencanaan bagi siswa sekolah dasar yang menjadi tujuan dari program tersebut.

Salah satu cara untuk mengatasi minimnya personil relawan Tagana adalah dengan merekrut personil Tagana. Alangkah baiknya rekrutmen personil menyasar khususnya pada pendidik, sehingga nantinya pendidik dapat melaksanakan pendidikan mitigasi bencana di sekolah masing-masing. Dengan demikian, program Tagana Goes To School dapat berjalan dengan efektif dan efisien.

\section{2) Pihak Sekolah yang Kurang Respon}

Berdasarkan hasil wawancara dengan relawan Tagana, masih banyak sekolah yang kurang respon terhadap program Tagana Goes To School ini. Beberapa dari sekolah tersebut masih kurang peka terhadap pentingnya mitigasi 
bencana sehingga Pendidikan kebencanaan belum bisa dilaksanakan. Tentu ini menjadi permasalahan tersendiri terkait bagaimana meyakinkan sekolah akan pentingnya Pendidikan kebencanaan yang harus diperoleh siswa-siswi.

Pihak sekolah yang kurang respon juga dapat terlihat pada pelaksanaan pendidikan kebencanaan di SDN 2 Wates Ponorogo. Pada saat pelaksanaan sebagian guru tidak mengikuti kegiatan ini. Ada yang di kantor dan hanya melihat saja. Padahal kegiatan ini seharusnya diikuti oleh seluruh warga sekolah tanpa terkecuali. Tujuannya agar guru nanti juga bisa menyisipkan pendidikan kebencanaan saat pembelajaran.

Kurang responnya pihak sekolah dapat diatasi jika sebelumnya terdapat koordinasi dengan pihak Tagana. Selain itu, pembetukan kader siaga bencana di sekolah juga akan membantu suksesnya program Tagana Goes To School. Pembetukan kader siaga bencana di sekolah dapat dilakukan, jika anggota relawan Tagana juga bersala di sekolah tersebut. Secara langsung akan terjadi ikatan atau hubungan yang berkelanjutan, sehingga program tersebut dapat berjalan dengan baik.

\section{SIMPULAN}

Peran Tagana dalam pendidikan kebencanaa bagi siswa sekolah dasar dapat terlihat dalam program Tagana goes to school. Pada program tersebut relawan Tagana melaksanakan pendidikan kebencanaan dengan melaksanakan sosialisasi dan simulasi mitigasi bencana. Peran Tagana, antara lain: 1) memberikan pengetahuan terhadap jenis-jenis bencana kepada siswa; 2) memberikan pengetahuan terhadap mitigasi bencana sesuai dengan jenis becananya, dan 3) melakukan simulasi mitigasi bencana. Dalam kasus ini, pendidikan kebencaanan lebih difokuskan pada bencana gempa bumi. Sedangkan untuk hambatan yang dihadapi tim Tagana Goes to School adalah keterbatasan personil dan kurangnya respon dari pihak sekolah.

Berdasarkan hasil penelitian yang telah didapat, maka peneliti memberikan saran atas penelitian ini, sebagai berikut: 1) meningkatkan kegiatan pendidikan kebencanaan tidak hanya menyasar kepada siswa sekolah dasar tetapi juga sampai ke Perguruan tinggi; 2) melaksanakan pendidikan kebencanaan kepada guru, sehingga mampu memberikan pemahaman tentang mitigasi bencana pada saat pembelajaran di kelas; 3) menambah personil relawan Tagana; dan 4) membuat kader siaga bencana di setiap sekolah, sehingga kegiatan pendidikan kebencanaan dapat terus berlangsung.

\section{DAFTAR PUSTAKA}

Abdulsyani. (2012). Sosiologi Skematika, Teori dan Terapan. Jakarta: Bumi Aksara.

AB, Syamsuddin, dan DN, Syakhruddin. (2018). Peran Anggota Tagana Terhadap Penanggulangan Bencana di Fakultas Dakwah Dan Komunikasi UIN Alauddin Kabupaten Gowa. Jurnal Mimbar Kesejahteraan Sosial, Edisi I, November 2018.

Badan Meteorologi, Klimatologi, dan Geofisika (BMKG). 2016. Gempa Bumi Tektonik Akibat Sesar Aktif Guncang Madiun dan Sekitarnya. (online). https://www.bmkg.go.id/. diakses pada tanggal 20 Februari 2020.

Badan Nasional Penanggulangan Bencana (BNPB). (2016). Buku Saku Tanggap Tangkas Tangguh Menghadapi Bencana. (online). https://bnpb.go.id/. Diakses pada tanggal 20 Februari 2020.

Carter, W. N. (2008). Disaster Management: "A Disaster Managers Handbook. Manila: Asian Develompent Bank.

Kementrian Pendidikan dan Kebudayaan RI. (2016). Mengenalkan Pengetahuan Bencana Alam Sejak Dini. (online). https://sahabatkeluarga.kemdikbud.go.id/, diakses pada tanggal 20 Februari 2020. 
Menteri Sosial RI. Peraturan Menteri Sosial Nomor 29 Tahun 2012 tentang Taruna Siaga Bencana (Tagana).

Rahman, Aulia. (2016). Peran Taruna Siaga Bencana dalam Mitigasi Bencana di Kabupaten Serang dan Sukabumi. Jurnal Sosio-Konsepsia. (online), https://ejournal.kemsos.go.id/index.php/SosioKonsepsia/article/view/311, diakses pada tanggal 28 April 2020.

Setyowati, Dewi Liesnoor. (2019). Pendidikan Kebencanaan. Universitas Negeri Semarang.

Sugiyono. (2009). Metode Kuantitatif, Kualitatif, dan R\&D. Bandung: Alfa Beta.

Tim Peneliti Puslitbang BMKG. 2011. Gempa Bumi Beruntun di Sekitar Ponorogo dan Trenggalek. (online). https://adoc.tips/tim-penelitipuslitbang-bmkg.html, diakses pada tanggal 20 Februari 2020.

Undang-undang Republik Indonesia Nomor 24 Tahun 2007 tentang Penanggulangan Bencana. 